\title{
MORE CHANGES
}

\section{Impact of SAPS restructuring on public order policing}

Bilkis O mar, Institute for Security Studies

bomar@issafrica.org

The effect of the pending South African Police Services (SAPS) restructuring process has raised concerns about the future of specialised policing units, including the Area Crime Combating U nits (ACCUs). The concerns relate to the fact that these units may lose their specialist abilities and become overburdened, ultimately leading to the end of the units in their current form. Considering that the trends show an increase in the number of public protests over time, it could be argued that the proposed changes may not be in the country's best interests. This article considers the implications of the proposed SAPS restructuring on the ACCU s.

$\mathrm{T}$ he ACCU s, or Public O rder Policing U nits, are specialist units tasked to manage public protests and major events. Due to the shifting political climate of the country, and the units' historically negative status (see the related article in SA Crime Q uarterly No 15 M arch 2006), public order policing underwent many necessary legal and structural changes between 1995 and 2002.

In 1995 the Internal Stability Division and the Riot Control U nits of the homeland police were merged under the new SAPS as part of the police's first transformation process. ${ }^{1}$ In 1997 the Public Order Police Unit was formed and in order to conform to the country's newly adopted democratic values, emphasis was placed on crowd management as opposed to crowd control.

In 2002 the units were further refined when the SAPS Standing O rder 262 on Crowd Management during $G$ atherings and Demonstrations was introduced. This document details the regulation of crowds in accordance with the principles of the Constitution. Despite the many changes, the units' sole function continued to be the policing of major events and protest marches.
This was to change in 2002 when the units' mandate did an about-turn, with public order police being tasked to do crime prevention and crime combating. The change reversed the core functioning of the units, with public order and crowd management becoming secondary functions. The restructuring was cemented by the change in name from Public Order Policing U nits to Area Crime Combating U nits. This served to further diminish their original purpose, giving crime fighting more prominence than crowd management.

The argument put forward in favour of the change was based on "the decrease in the number and intensity of major demonstrations, violent marches and labour unrest since the inception of the new democracy". ${ }^{2}$ Furthermore, the new Public Finance Management Act 1 of 1999 also demanded 'value for money' budgeting. ${ }^{3}$

\section{Trends in public protests}

Considering that the SAPS' main reason for restructuring the units in 2002 was the drop in the number of protest events, it is worth reviewing the relevant trends. Data on public protest incidents since 1997 show that although the number of 
marches did decline up to 2002, the number of ongoing events was still considerable - significant enough to warrant specialised attention from the police. Moreover, the number of incidents has steadily increased between 2002 and 2005 (Figure 1).

Public events and marches are recorded by the SAPS on the Incident Registration Information System Business Intelligence System (IRIS-BIS). This system was developed in 1992 and its main purpose has been to standardise information so that it can be easily understood and interpreted by all relevant parties. ${ }^{4}$ It also serves to replace the manual system of recording events.

Since its inception, the system has been reconfigured and re-classified twice. It has an extensive classification system, recording incidents in the following categories:

- crowd management (peaceful);

- crowd management (unrest);

- unrest incident (other);

- support; and

- crime prevention.

The recorded incidence of crowd management (peaceful and unrest related) shows that public protests in the country declined from 1998 to 2002 (Figure 1). According to O livier and Marks, the substantial increase between 1997 and 1998 can be attributed to an increase in non-violent incidents (music festivals, gatherings, processions, political gatherings, sports gatherings), and the new category of 'meetings' used by the SAPS. ${ }^{5}$

The trends suggest that it was not unreasonable for the SAPS management to have decided to revisit the functioning of the public order policing units in $2001 / 02$, especially when the units could be effectively utilised for crime prevention and the implementation of the $\mathrm{N}$ ational Crime Combating Strategy (NCCS). ${ }^{6}$ However, despite these decreases, the total number of incidents remained high, even though expectations at the time may have been that under the new democratic government, levels of public protest would decline.

Ironically, since the formation of the ACCUs in 2002, with their focus on crime prevention over crowd management, the number of public protest incidents has increased steadily, reaching a high of 10,162 events in 2005 (an increase of 50\% between 2002 and 2005). The increase has meant that the specialist crowd management function of the ACCU s has become more essential.

Of even more significance is that the rate of increase in the last three years has been faster for violent incidents than for peaceful ones: violent or unrest crowd incidents increased by $64 \%$ between 2002 and 2005 , compared to a $49 \%$ increase for peaceful events.

Figure 1: Total violent and peaceful crowd management incidents, 1997-2005

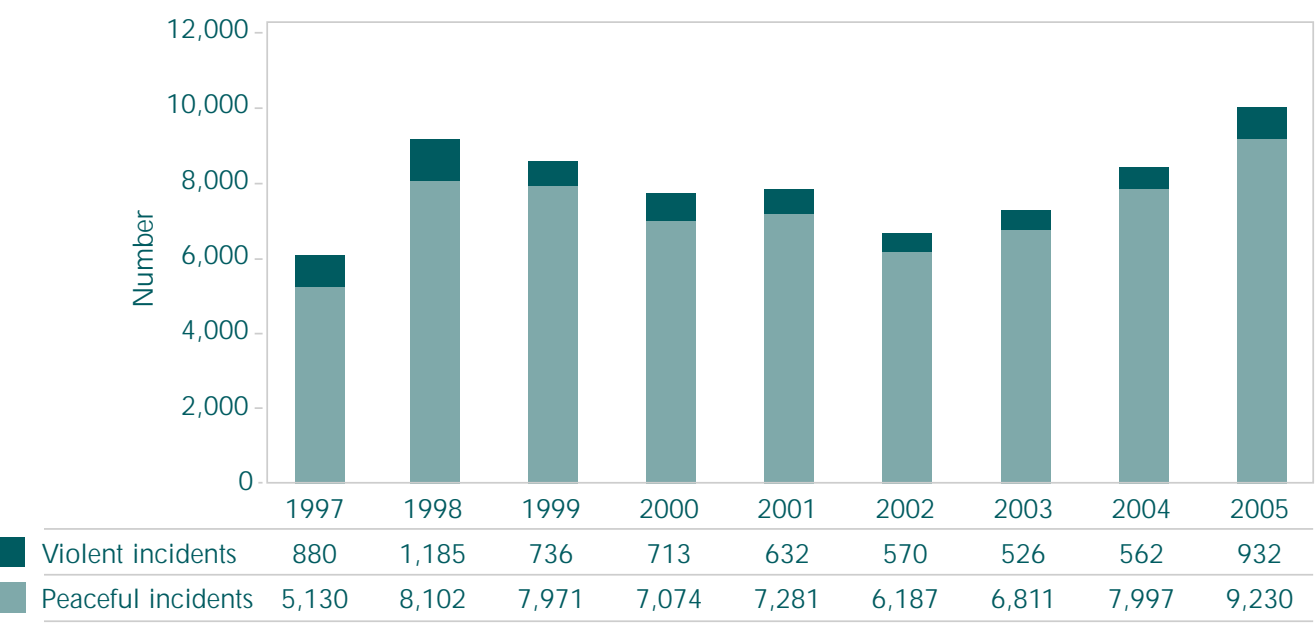

Source: SAPS O perational Response Services, Pretoria 
Another worrying trend is that, based on an examination of the issues driving the protests, it appears that crowd management incidents are likely to increase in future. The IRIS-BIS database shows that service delivery and work-related concerns have been featuring prominently in the majority of public protests in the last few years. Considering that these issues are unlikely to be resolved in the short term, it is to be expected that public protests about these matters will continue in future.

The above concerns illustrate the importance of retaining the specialist skills of the ACCUs. These can be maintained only if the specialist abilities are continuously honed. Specialisation suggests the ability to excel at a particular duty or function with the benefit of particular technical skills. For the ACCUs, this entails members working together as a unit, continuous rigorous training, maintenance and upgrading of equipment, and strict discipline. It also means adhering to the principles and laws governing the unit.

According to Waddington, the advantages of specialisation are clear enough: it ensures the highest standard of competence; officers work together as a team and come to know each other's capabilities and acquire trust in one another so that they can act as a cohesive unit rather than as a collection of individuals; their frequent exposure to operational conditions familiarises them with the vagaries of actual operations so that they are less likely to be caught off-guard; and their elite status raises morale and can become an incentive for maintaining strict discipline. ${ }^{7}$

In essence, this points to the fact that a specialised unit's capabilities should not be diluted, especially to the extent that it runs the risk of losing that capability. The decentralisation of the public order policing units to the SAPS area level in 2002, together with the dual tasks of crime combating and crowd management, probably weakened the specialist capacity of the units with regard to policies, implementation, management and training.

\section{Proposed restructuring: mid-2006}

In mid-2006 the SAPS announced a major restructuring of the entire organisation, which meant yet more changes for the ACCUs. The restructuring was based on evaluations undertaken to explore factors that were hampering police functioning, including, among other things, "a duplication of functions, the impeding of effective command and control, and slow delivery". ${ }^{8}$ In addition, it was found that "there [were] too many levels of authority in the police".

Currently, the SAPS functions on four levels: national, provincial, area and station. The planned restructuring will reduce these to three levels, eliminating the area level. O ne of the arguments made for the restructuring was that it was "in line with the Constitution". ${ }^{10}$ According to the Constitution, "the national police service must be structured to function in the national, provincial and, where appropriate, local spheres of government.' ${ }^{11}$ Thus, elimination of the area level means adherence to the principles of the Constitution.

The motivation behind the restructuring is the strengthening of police stations and the improvement of service delivery to the public at station level. Under this arrangement, station commissioners will be delegated more powers and will be given additional human and physical resources to manage. Stations will be clustered in groups of five or six, and will deal with cross-station issues and crime problems.

Each cluster will be supervised by an 'accounting station', which will be determined by the crime threat analysis. The accounting stations are basically bigger stations rendering a support service to the cluster of other stations in their jurisdiction. The services will include human resources, financial, administrative, and supply chain management.

\section{The effect on the ACCUs}

There are 43 policing areas nationally with 43 ACCU units (one in each area) with an operational capacity totalling $\pm 6,300$ (excluding civilian and support personnel). ${ }^{12}$ The proposed restructuring would see the 43 areas close down and the ACCU s deployed to station level.

Gauteng for example, is divided into seven policing areas: Johannesburg Central, East Rand, North 
Rand, West Rand, Vaal, Pretoria, and Sow eto and includes a total of 122 police stations. The seven areas will close down and the 122 stations will be clustered around approximately 25 accounting stations. Thus, the Johannesburg Central area, currently responsible for managing 21 stations, will close down and the 21 stations will be clustered around approximately four accounting stations.

The ACCU component in Gauteng consists of approximately 1,383 operational members. Johannesburg Central area currently has 179 operational ACCU members. With the restructuring, approximately 45 operational members will be deployed to each accounting station. By locating the ACCUs at the accounting stations, the intention is that personnel capacity and principles of teamwork will be maintained, and equipment and training programmes will be housed under one roof. $O$ ther crime prevention functions performed by ACCU members will also be managed from these accounting stations, apart from those managed by the provincial office.

The responsibility of the SAPS O perational Commander of Response Services at the provincial level will be to implement policy with regards to public order policing, to plan, coordinate and mobilise members and cross-station operations, and to maintain training programmes and equipment of the public order police.

The outcome of this new arrangement is to increase crime prevention support to the stations, to have the crowd management capacity closer to station level, to have capacity available for borderline operations, and to assist detectives in dealing with dangerous criminals.

As with most restructuring processes, the above is not without challenges. O perationally, further decentralisation of the units could result in a breakdown of their functioning. In Gauteng, for example, members will have to be deployed from 25 accounting stations (as opposed to seven at the moment) to mobilise for an event. The fundamental principles of specialisation - teamw ork and cohesiveness - may disintegrate because of the fragmentation of the units. This will then impact on training of members, and maintaining a full platoon will be impossible given that capacity is already too minimal, that members work in shifts, and that some are away on leave.

Apart from the above, at the conceptualisation stage of the restructuring, operational members at national, provincial and area offices do not appear to have been consulted about the changes. ${ }^{13}$ Members on the ground who would be most affected by the restructuring were not notified about the process, despite a national communication drive undertaken by the team responsible for the restructuring. ${ }^{14}$ Communication seems to be taking place via informal channels and members are concerned that the unit is losing its identity, will be deskilled and is being shut down. The result is much uncertainty and low morale among police officials.

\section{Rethinking the restructuring}

However, in August 2006 the SAPS team driving the restructuring process decided, after some consultation, on a redesign of the ACCUs.

The new design proposes that a portion of ACCU members be deployed to do crowd management, while another portion be tasked to do crime prevention. ${ }^{15}$ In Gauteng, for example, of the 1,383 operational members, 614 will be deployed to do crowd management while approximately 769 members will be deployed to stations to carry out crime prevention duties.

The crowd management component will be divided into three new public order units: Johannesburg, East Rand and Pretoria. ${ }^{16}$ The Johannesburg unit will be based at Diepkloof and will incorporate the Soweto and West Rand units. This unit will be allocated 225 operational members. The East Rand unit will consist of the Vaal and North Rand operating from Nufield, and will be allocated 187 members. The Pretoria unit will be allocated 202 operational members and operate from Rosslyn. If more than the existing capacity is required to police an event in one of the three units' areas, members from the other two units will be recruited to assist with crowd management.

In terms of crime prevention distribution, not all police stations in Gauteng will necessarily benefit 
from the additional human resources. Instead, distribution will be done based on a crime threat analysis. ${ }^{17}$ Furthermore, visible policing and other crime prevention initiatives will be concentrated in flashpoint areas.

\section{Challenges of the new design}

The restructuring of the ACCUs is still in design phase. Given this, weaknesses are easily identifiable, issues may yet be addressed, and conclusions reached now may be premature. How ever, the concerns need articulating for the very reason that they exist.

The rearrangement of the units (in Gauteng, at least) translates to three geographically bigger areas that each public order unit is responsible for, compared to the seven smaller areas under the previous arrangement. However, the larger geographical areas do not come with more operational members. In fact, of the 1,383 operational members in Gauteng, only 614 will be retained to do crowd management.

Thus, the Johannesburg unit, which previously had 197 operational members for one area, now currently has 215 operational members for a total of three areas (including West Rand and Soweto). Whether the allocated 614 members will be adequate to carry out the crowd management function remains to be seen. Perhaps the absence of the crime combating function will make the task possible, and will alleviate concerns regarding the deskilling of the specialist function of the units.

The above is of course based on the assumption that the remaining crowd management members are not once again drawn into carrying out crime combating duties. It is also unclear whether the members allocated to do crime combating duties will also be utilised for crow d management. Given the broad purpose that the SAPS hopes to achieve with the restructuring, it is possible that these members will be incorporated into visible policing and cease to do crowd management.

The issue of responsibility and accountability of the units is still undecided. The risk exists that if the units become the responsibility of accounting station commissioners, members may be used to carry out crime combating functions. Clearly, the preferred solution would be that the units are accountable to the provincial office. This would also remove the concern of administrative and financial responsibility, given that it would be standardised and better managed at the provincial office.

Perhaps the most pressing concern is the status and placement of current members. Given the separation of functions, ACCU commanders will have to be reallocated positions, operational members will have to be divided between crowd management or crime combating positions, and civilian staff will have to be relocated to new positions. The criteria for selection and distribution of members will be challenging.

Travel and transport of members will have to be given due consideration, given the tightening up of the SAPS transport policy. ${ }^{18}$ State vehicles, previously used to transport members, will no longer be used for this purpose. Mobilisation of members at short notice will also have to be factored in if members are placed far from their homes.

All in all, the above concerns have resulted in discontent and low morale among some members, which could probably be resolved if communication is improved.

\section{Taking the process forward}

As with most restructuring processes, the impact of the proposals will be far-reaching. The ACCUs will once again revert to being called Public 0 rder Police. This will mean that members will need to go through another identity and mindset change. Police organisations have an intrinsic cultural capital that does not readily accommodate change. ${ }^{19}$ How the units cope with yet another change will be worth monitoring.

The difference between the two types of restructuring proposed this year is clear. While the mid-2006 design would have been an operational nightmare, the later design seems better thought out. If anything, it serves to secure the specialist component of the units for the time being.

The concern now, however, is that the ACCU's capacity is going from being 'deskilled' to being 'depleted'. O ne wonders at the prominence decision 
makers in the SAPS have attributed the ACCUs, given that they have to police approximately 10,000 public protests annually. While their specialist skills may be restored with the proposed redesign, it would mean more work for fewer members.

As noted, problems of service delivery and public protests that motivate most protest marches are at an all-time high, but of more concern is the increase in violent incidents. The specialist skills of the ACCUs in handling these events should not be underestimated. In order to retain this skill it is vital that the units undergo continuous, rigorous, training.

Given the challenges of selecting and re-distributing ACCU members, a panel, consisting of operational managers and commanders from each area, should be appointed. This will ensure the retention of the best members for the crowd management component, and will help accommodate members' transport problems.

If the roles and functions of the two components are clearly spelled out, tasks previously carried out by ACCU members such as borderline control, crime prevention operations, fixed and mobile roadblocks, guard duties and escort duties, should no longer be done by the crowd management component of the public order unit. Instead, the operational members deployed to do crime combating should incorporate these functions as part of their new duties.

The SAPS management were quite artful at the conceptual phase of the restructuring. The backing of the police unions was obtained at the outset, which meant that the door for protests and grievances was firmly closed. The steadfast support of the unions is evident from this PO PCRU statement:

It is only logical to expect a handful of some within the policing fraternity to be unhappy as a result of this development that will see them leaving their air-conditioned offices and revolving chairs to be directly involved in the war against crime from the most decisive front, which are the streets of our country. ${ }^{20}$
While it is surely the intention of the design team to act in the best interests of the country as well as SAPS members, there is currently much uncertainty and insecurity among ACCU members. SAPS management has to take cognisance of this and regularly communicate the process to members in order to facilitate an easier transition.

\section{Endnotes}

1 B O mar, Can our public order police still deliver? SA Crime Q uarterly, No 15, Institute for Security Studies, March 2006, p 9.

2 SAPS Policy: Division: O perational Response Service: The Establishment and Functioning of Area Crime Combating Units (ACCU's), 2004, p 1.

3 Ibid.

4 Ibid

5 J Olivier and M Marks, The N everending Story: Reforming Public Order Policing in South Africa, in 0 Fillieule and D Della Porta (eds), Police et $M$ anifestants: $M$ aintien de l'orde et gestion des conflits, Paris, Presses de Sciences Po, 2006, pp 8-10.

6 The NCCS was launched in 2000 as a high density, cordon, search and seizure operation to combat crime in hot spots most affected by crime.

7 PAJ Waddington, The Strong Arm of the Law, Armed and Public Order Policing, Clarendon Press, Oxford U niversity Press, N ew York, 1991, p 54.

$8<$ <ttp://www.issafrica.org/index.php> M edia Statement, Briefing Session on the Impact of SAPS Restructuring on the Policing of Violence against Women and Children, 31 May 2006, Joint Media Release by the SAPS and the Institute for Security Studies.

9 Comment by Assistant Commissioner De Wit, op cit.

10 Ibid.

11 The Constitution of the Republic of South Africa, 2006, p 119.

12 B O mar, op cit, p 9.

13 Informal conversations with ORS and ACCU members at national, provincial and area offices.

$14 \mathrm{Ibid}$.

15 Telephonic interview with senior SAPS member, SAPS national head office, 7th September 2006.

16 Interview with senior SAPS member, SAPS provincial office, September 2006.

17 Telephonic interview, SAPS member, national head office.

18 Interview with SAPS member, SAPS provincial office, September 2006.

19 M Marks, Transforming the Robocops: Changing Police in South Africa, University of Kwazulu Natal Press, Pietermaritzburg, 2005, p 241.

$20<h t t p: / / w w w . i o l . c o . z a / g e n e r a l / n e w s / n e w s p r i n t$. php?art>, news article, Restructuring will decrease crime - Selebi, Independent O nline, 27/09/06. 
Cover photograph

By Denis Farrell/PictureNET Africa

A supporters of Jacob Zuma protest outside the High Court in Johannesburg, during the ongoing trial of South Africa's former deputy president.

Zuma, the man once groomed to be South Africa's next president defended himself against charges that he raped an HIV-positive family friend and argued in graphic detail that it was consensual sexual intercourse.

Copyright in this volume as a whole is vested in the Institute for Security Studies, and no part may be reproduced in whole or in part without the express permission, in writing, of the ISS.

It should be noted that any opinions expressed are the responsibility of the authors and not of the ISS, its Advisory Board, the Trustees, or any funder or sponsor of the ISS.

ISSN: 1991-3877

First published by the Institute for Security Studies

Pretoria office:

P O Box 1787, Brooklyn Square, Pretoria 0075 SOUTH AFRICA

Tel: + 2712346 9500/2 Fax: +27 124600998

Email: iss@issafrica.org

www.issafrica.org

Editors: Antoinette Louw email: alouw@issafrica.org Bea Roberts email: bearoberts@wisenet.co.za Design and production: Image Design

Repro and print: Remata iNathi 